\title{
PRACTICAL AND APPLIED APPROACH FOR LEARNING GIS IN LANDSCAPE ARCHITECTURE EDUCATION
}

\author{
Galev E., Prof., PhD, University of Forestry, Sofia, Bulgaria \\ DOI: https://doi.org/10.31435/rsglobal_conf/25122020/7308
}

\begin{abstract}
The paper reviewed the current state of GIS education at landscape architecture students in Bulgaria. Nowadays profession of landscape architecture cannot be practiced successfully without skills and abilities of geographic information system (GIS). An example is given in this study for using well known and real situation at GIS education. The basic stages in landscape planning process are tracked out. Our specific example involved the creation of a digital project for landscape-ecological evaluation involving data set of a well-known for the students forest region examined during their previous practical studies. Graphical and semantic data are easy to understand and make a good profit of educational process.
\end{abstract}

Keywords: GIS, education, landscape science, student classes, thematic mapping

Introduction. In teaching GIS (Geographic Information Systems) in laboratory student's classes always is used a sample object which has previously created database. The aim of semester project is the students to apply what they have learned in a situation close to real life. In most cases, however, the investigated territory is absolutely unknown to the students and does not cause any associations in their minds. As is well known in geographical sciences, the importance of the association of pre explore the terrain of a particular area, which is used as an object of study is extremely high and is the most secure prerequisite for the successful conduct of the educational process.

At present, the applied significance of such approaches is very well proven in the activities in spatial planning and design, tourism and in general in all spheres of modern life [2].

Material and methods. The rapid entering of GIS technology in all walks of life have mass study by experts in various fields of science and practice. According to [1], the introduction of GIS as an educational discipline is the most important and necessary to be done in most universities, because that students can best perceive and master this so complicated matter. As the [4] successful implementation of lessons and assimilation of the taught material greatly depends on the apt choice of experimental subject of study in the laboratory. [3] formulate a similar statement by specifying different choices appropriate sample learning objects depending on the specialty of the students.

The specific examples discussed in this article is taken from the laboratory work on the course "Landscape science" of students in "Landscape architecture" at the University of Forestry in Sofia, Bulgaria and includes:

- Understanding the basic landscape components and their spatial distribution on the territory of Bulgaria.

- The creation of a project for landscape and recreational evaluation of a particular forest area. They trace the various stages in the process of landscape and environmental planning in the territories and in later phases of landscape development and landscaping design.

Results and discussions, including research limits and advantages. At familiarizing students with the landscape forming components on the territory of Bulgaria is used well studied in the average high school course material of natural geography and well-formed association contours of our country from various maps. Created during classes schemes for individual landscape components have two main tasks in didactic terms:

- to create visual association for spatial location and spatial relationships of specific landscape features that can only be described as purely empirical knowledge of the landscape. In all geographical sciences, such as "Landscape science" this kind of "knowing things" is mandatory and prerequisite;

- to help students understand and realize what exactly is the philosophy of geographic information systems. This is achieved by making a number of schemes. Self drawing and coloring of these schemes in the working environment of CAD / GIS software helps a lot for a proper understanding of the relationship between graphic and semantic data (Fig. 1). By analogy with the regions in each of manufactured in classes schemes differentiate and landscapes of the lower levels (regional and local) of landscape development projects. Almost all objects there are with an area dimension. 

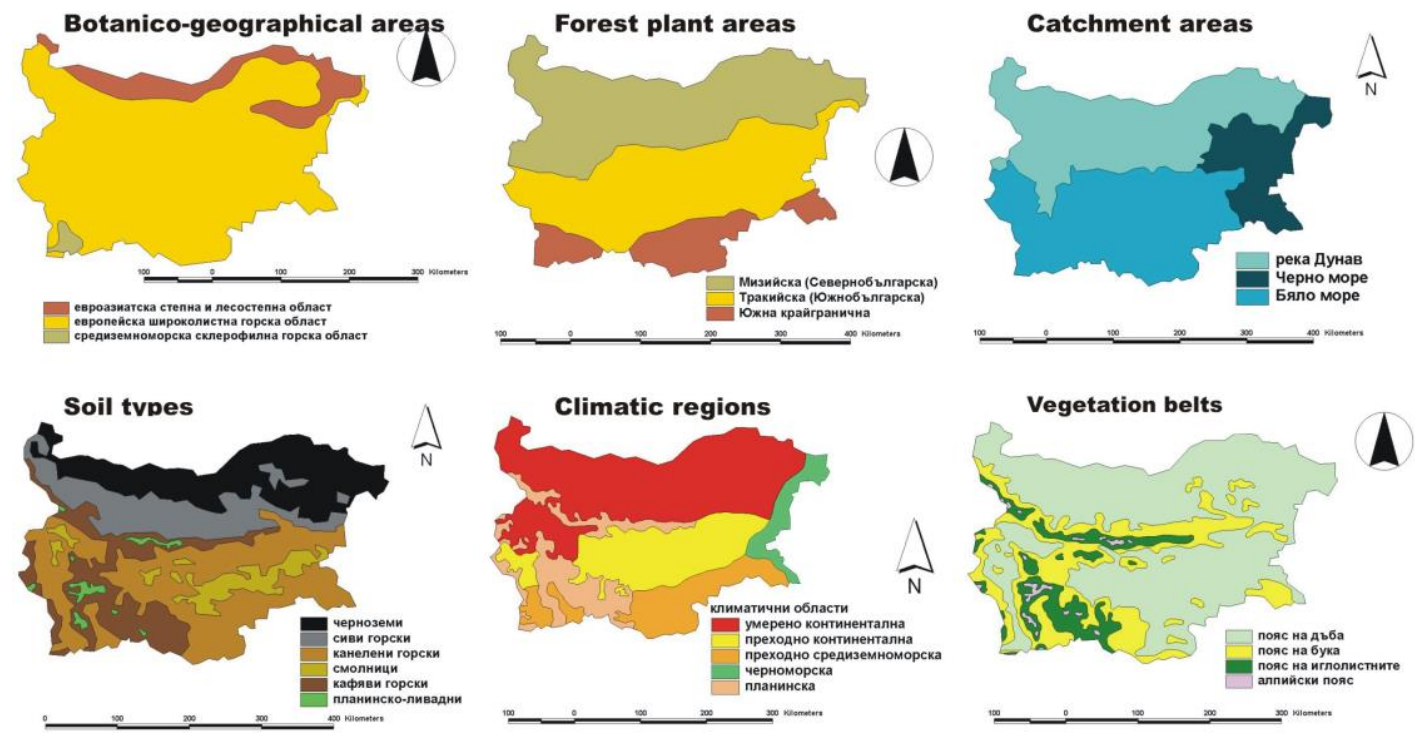

Fig. 1. Each of these elementary schemes drawn in the working environment of AutoCAD and colored in ArcView represents in itself a very small by its volume and content geographical information system.
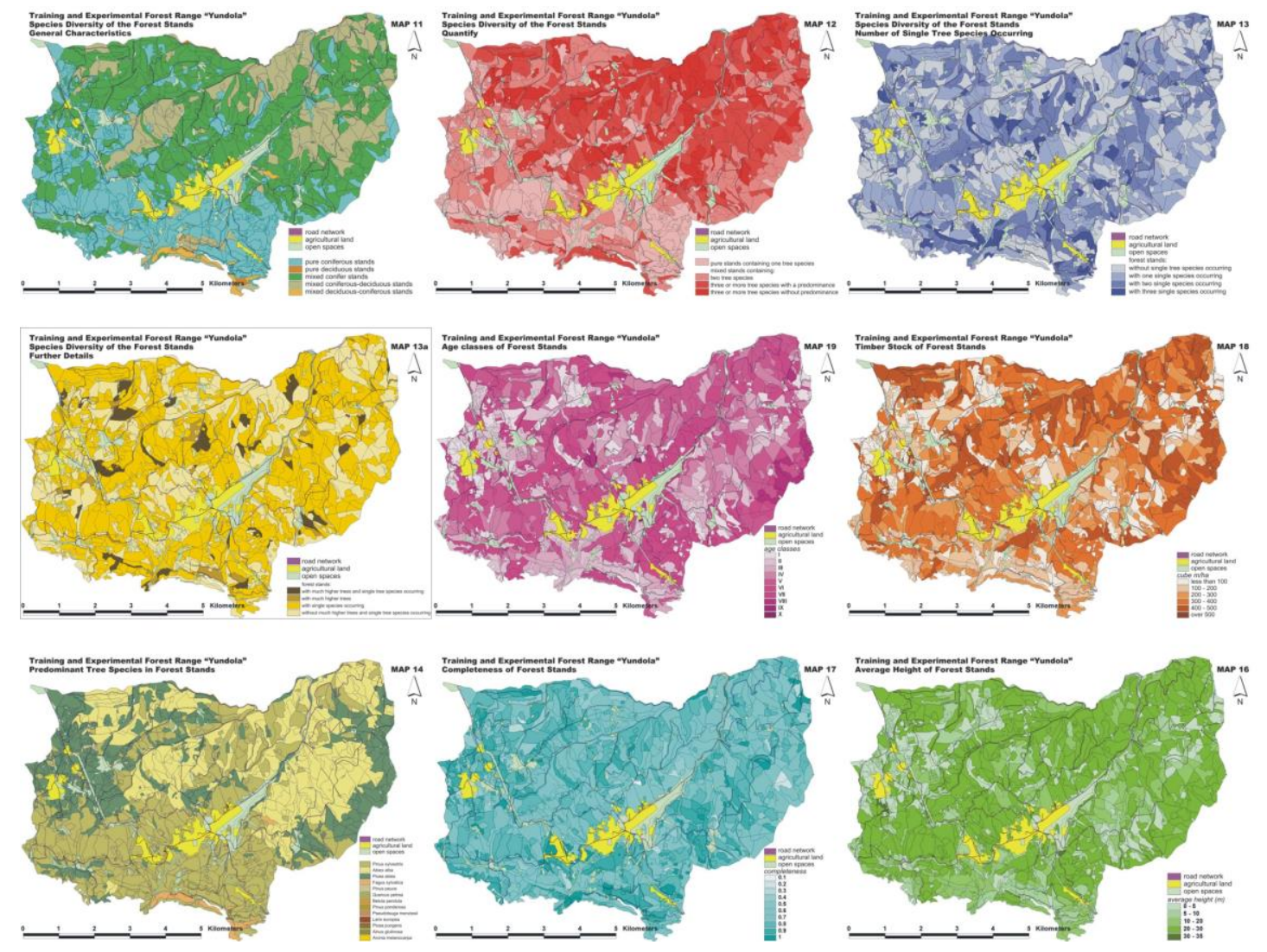

Fig. 2. Thematic maps.

For awareness to the philosophy and operation of GIS contributes the development of study for landscape-recreational evaluation of a particular forest area. During the previously held practice this territory was visited and reviewed and in addition there are hundreds of single and panoramic photographs that are available during the classes and can recall the landscape characteristics of each fragment of the examined terrain. For several laboratory classes are made a series of thematic maps illustrating the diversity of individual landscape characteristics (Fig. 2).

Thus it becomes possible to make a comparison between the photo card and the existing terrain (Fig. 3). This contributes to the emergence of new and more complete ideas of students for the real possibilities of GIS and how to use them in the field of landscape architecture in a real field situation in our conditions and existing in our country graphics and semantic information. 

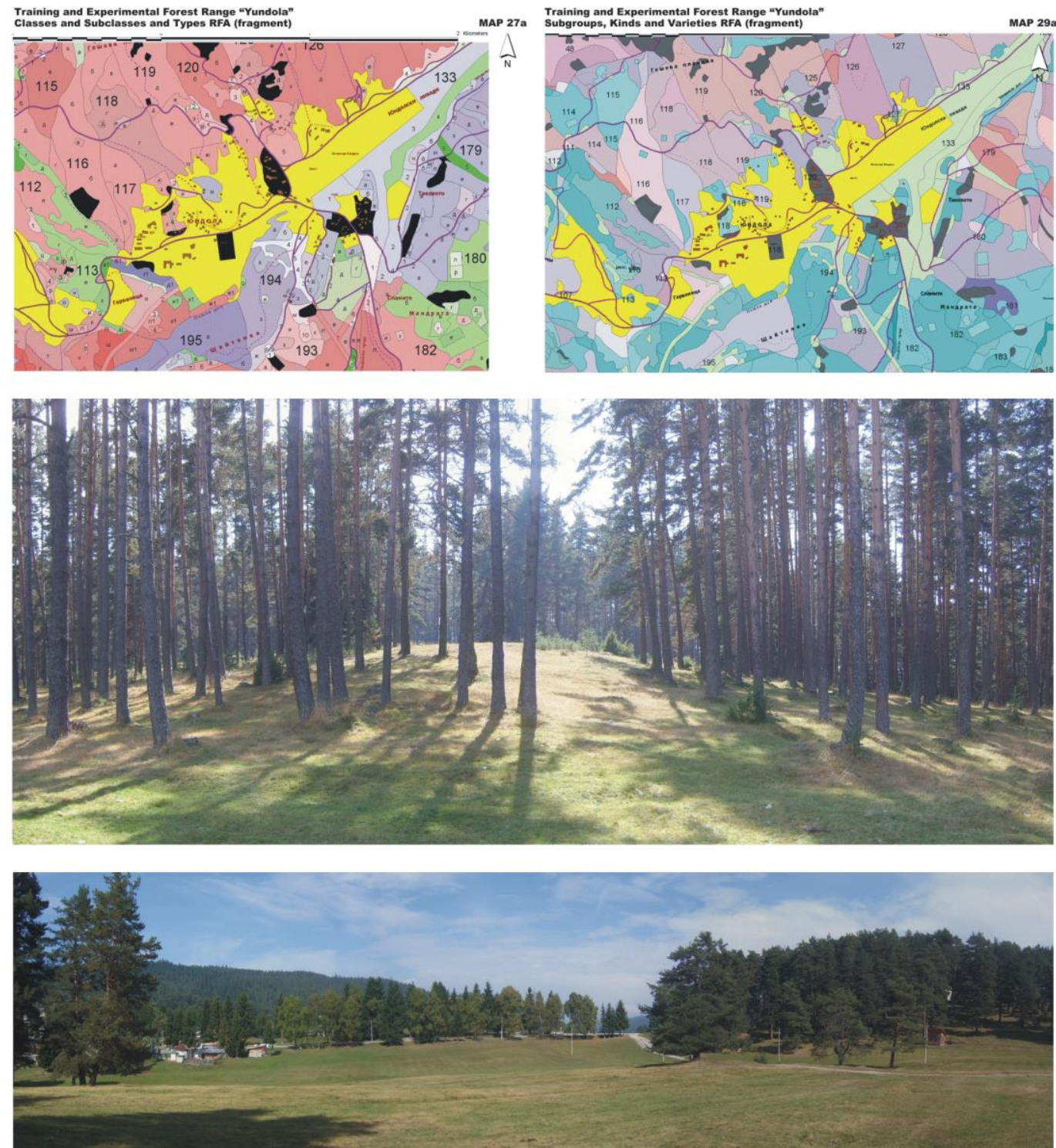

Fig. 3. Comparison between the portrayal of the scheme and existing on the field.

Conclusions. The complexity of GIS applications is large enough to hope that the training will be effective if used "hijacked" examples that are far from the learner categories of thinking (eg database and support training programs containing in the software product). Even a teacher is a great expert in the use of GIS software, he can not be both a specialist in all areas of life where GIS software is used. To optimize the teaching of GIS and to increase the effectiveness of teaching and student interest, teachers can choose a landscape approach in which the object of study is specific terrain that students have previously observed or were introduced to them by photo materials or educational films.

Graphical data are more easily readable and semantic information is much easier to understand when there is the association for the familiar terrain features and general landscape features of the research area.

\section{REFERENCES}

1. Deliiska B., Todorov B., Danchev A. 2004. Educational aspects of geoinformatics implementation (case study of Bulgaria), Proceedings of "3-rd GIS Days in Turkey/October 6-9, 2004", 163-169.

2. Gurkova, M. 2015. Features of development intervention needs of cultural tourism in forest areas. Journal of Management and Sustainable Development, University of Forestry, Sofia, Bulgaria, 2015/6, vol.55, pp. 91-96; ISSN 1311-4506

3. Kerski, J. 2003. The Implementation and Effectiveness of Geographic Information Systems Technology in Secondary Education. Journal of Geography, 102(3): 128-137.

4. Laituri, Melinda, and Sophia Linn. 2001. Graduate students plus Grade School (K-12) plus Geography Standards plus GIS = Great Success ? Proceedings of the 1999 ESRI User Conference. 